\title{
On the Molecular Weight Dependence of the Second Virial Coefficient of Polystyrene in Toluene
}

\author{
Lina ZHANG, Dajian QIU ${ }^{\dagger}$, and Renyuan QIAN* \\ Chemical Department, Wuhan University, Wuhan, China \\ *Institute of Chemistry, Academia Sinica, Beijing, China
}

(Received November 12, 1984)

\begin{abstract}
The molecular weight dependence of the second virial coefficient $A_{2}$ was measured osmometrically for polystyrene in toluene at $30^{\circ} \mathrm{C}$ in the molecular weight range of (6.6$445) \times 10^{3}$ and compared with the results of our previous light scattering measurements. It was found that for $M$ (molecular weight) $>4.5 \times 10^{4}, A_{2}{ }^{\text {osm }}$ and $A_{2}{ }^{1 \text { s }}$ agreed fairly well. However for $M<3 \times 10^{4}$ the former was much larger than the latter and followed the relation $A_{2}=0.964$ $M^{-1 / 2}-4.36 \times 10^{-3}$.

KEY WORDS Polystyrene / Toluene / Second Virial Coefficient / Osmometry / Light Scattering /
\end{abstract}

The molecular weight (MW) dependence of the second virial coefficient $\left(A_{2}\right)$ is of considerable interest in the theory of polymer solutions. One of the chief difficulties in the investigation of $A_{2}$ lies in the embarrasing incapability of using a single experimental technique to cover a wide range of $\mathrm{MW}$, say from $10^{3}$ to $10^{6}$, although monodisperse polystyrene (PS) samples available since the sixties have made it possible to get around polydispersity effects. Recently, we have published the results of $A_{2}$ measurements on PS in toluene at $25^{\circ} \mathrm{C}$ by low angle laser light scattering over a range of $\mathrm{MW}$ from $4 \times 10^{3}$ to $2.6 \times 10^{6} .{ }^{1}$ One of the present authors ${ }^{2.3}$ has developed a semi-permeable membrane which can be used to measure $\mathrm{MW}$ by dynamic osmometry down to $10^{3}$.

Therefore, we were interested in measuring $A_{2}$ of PS in toluene by osmometry in the MW range of $6 \times 10^{3}-4.5 \times 10^{5}$ and comparing the results with $A_{2}{ }^{1 \mathrm{~s}}$ obtained previously.

\section{EXPERIMENTAL}

\section{Samples}

Samples used here were ten monodisperse polystyrenes as shown in Table I. The samples No. 1 (A-5000), No. 2 (500-A), and No. 6 (F-4) were purchased from Japan, the sample No. 9 from England, and the samples No. 3 (7101), No. 4 (ND-4), No. 5 (JD-2), No. 7, No. 8 (ND-6) and No. 10 (ND-9) from China.

\section{Solvents}

Toluene, AR, $\rho^{30}=0.8563 \mathrm{~g} \mathrm{~cm}^{-3} ; \quad N, N$ dimethylformamide (DMF), AR; ethanol $(\mathrm{EtOH}), \mathrm{CP}$; acetone $\left(\mathrm{Me}_{2} \mathrm{CO}\right), \mathrm{CP}$, all were used without further purification.

\section{Osmometer and Semi-Permeable Membrane}

A modified Bruss osmometer of small cell volume made of stainless steel was used for osmotic pressure measurements. A semi-permeable membrane was made from cellophane obtained from Tianjin No. 4 Paper Mill in China, first by soaking it in $20 \%$ EtOH for 20

\footnotetext{
${ }^{\dagger}$ Present Address: Hubei Chemistry Institute, Wuhan, China.
} 
Table I. Molecular weight dependence of $A_{2}$ of PS in toluene at $30.0 \mathrm{C}$ by osmotic pressure measurements

\begin{tabular}{|c|c|c|c|c|c|}
\hline \multirow{2}{*}{$\begin{array}{c}\text { Samples } \\
\text { No. }\end{array}$} & \multicolumn{2}{|c|}{ Nominal values } & \multirow{2}{*}{$\begin{array}{c}\text { Concentration } \\
\text { range } \\
\text { (in } 10^{-3} \mathrm{~g} \mathrm{~cm}^{-1} \text { ) }\end{array}$} & \multirow{2}{*}{$M_{n}^{o s \mathrm{~m}} \times 10^{-4}$} & \multirow{2}{*}{$\frac{A_{2}^{\mathrm{osm}} \times 10^{4}}{\mathrm{~mol} \mathrm{~cm}^{-3} \mathrm{~g}^{-2}}$} \\
\hline & $M_{w} \times 10^{-4}$ & $M_{w} / M_{n}$ & & & \\
\hline 1 & 0.67 & 1.04 & $0.4-1.8$ & 0.66 & 74.9 \\
\hline 2 & 0.91 & 1.01 & $0.6-2.8$ & 0.92 & 58.0 \\
\hline 3 & 1.47 & - & $0.7-3.4$ & 1.46 & 38.1 \\
\hline 4 & 2.44 & 1.03 & $1.2-5.8$ & 2.33 & $188_{1}$ \\
\hline 5 & 3.40 & 1.03 & $1.5-7.3$ & 3.26 & $8.7_{4}$ \\
\hline 6 & 4.39 & 1.01 & $1.8-8.8$ & 4.43 & $5.1_{3}$ \\
\hline 7 & 10.0 & - & $3.2-16$ & 8.90 & $3.8_{2}$ \\
\hline 8 & 13.3 & 1.06 & $3.8-19$ & $12.4^{\mathrm{a}}\left(13.0^{\mathrm{b}}\right)$ & $4.4^{\mathrm{a}}\left(4.6_{7}^{\mathrm{b}}\right)$ \\
\hline 9 & 20.0 & - & $5.2-13$ & 17.9 & $4.3_{8}$ \\
\hline 10 & 53.3 & 1.17 & $6.9-17$ & $\begin{array}{r}44.5^{\mathrm{a}}(43.6) \\
\quad\left(46.8^{\mathrm{b}}\right)\end{array}$ & $\begin{array}{r}3.04^{\mathrm{a}}(2.98) \\
\left(3.0^{\mathrm{b}}\right)\end{array}$ \\
\hline
\end{tabular}

a Determined by static osmometry.

b Determined by an automatic membrane osmometer of Wescan Inc.

days and then by transferring it to absolute EtOH, to EtOH-DMF $(1: 1)$ and finally to $\mathrm{DMF}$, for $5 \mathrm{~h}$ in each bath. The cellophane membrane was then rinsed at least three times with fresh DMF and kept in DMF. For the determination of $M_{n}$ (the number-averagemolecular weight) and $A_{2}$ of PS in toluene, the membrane was first transferred from DMF to $\mathrm{Me}_{2} \mathrm{CO}$ and further to $\mathrm{Me}_{2} \mathrm{CO}$-toluene and then mounted on the osmometer. It was conditioned in toluene before each osmotic pressure measurement. This gradual change of solvent from DMF to toluene via $\mathrm{Me}_{2} \mathrm{CO}$ was found necessary, since otherwise the regenerated cellulose membrane would shrink drastically when it was transferred directly from DMF to toluene and thus lost its solvent permeability. The semi-permeable membrane thus prepared has a permeability constant of $0.26 \times$ $10^{-13} \mathrm{~cm}^{3} \mathrm{sg}^{-1}$ in toluene when estimated according to Kuhn, ${ }^{4}$ and hence it can be used to measure molecular weight down to $10^{3} .^{3}$

\section{Osmometry}

Dynamic osmometry was mainly employed to determine osmotic pressures since its measuring time is much shorter than that for static osmometry, and hence the leak of low molecular weight components does not seriously affect the observed values of osmotic pressure. In the dynamic osmometry the external applied pressure difference across the semi-permeable membrane extrapolated to zero flow rate was taken as the osmotic pressure. The experimental relationships between applied pressure and flow rate were linear and the extrapolated values from the higher and lower external applied pressures than the expected osmotic pressure agreed with each other as shown in previous papers. ${ }^{2,3}$ It was already reported ${ }^{3}$ that molecular weights of polystyrenes having low molecular weights obtained from the dynamic osmometry are in good agreement with those obtained from static osmometry and vapor pressure osmometry. In this work, moreover, molecular weights and second virial coefficients of polystyrenes having higher molecular weight (No. 8 and No. 10) were determined by the static and dynamic osmometries, and also by using an automatic membrane osmometer of Wescan Inc. As shown in Table I they agree well with each other. These results indicate that reliable data of osmotic pressure can be obtained by the dynamic osmometry.

Number-average molecular weight $M_{n}$ and 
second virial coefficient $A_{2}$ were evaluated from the osmotic pressure $\pi$ for a series of solution concentration $c$ using the relation:

$$
(\pi / c)^{1 / 2}=\left(R T / M_{n}\right)^{1 / 2}\left[1+(1 / 2) A_{2} M_{n} c\right]
$$

The use of this equation implies that the third virial coefficient of the solution has been partially taken into account. ${ }^{5}$

\section{RESULTS AND DISCUSSION}

The results of osmotic pressure measurements on 10 monodisperse PS samples in toluene at $30^{\circ} \mathrm{C}$ are shown in Figure 1 . The $M_{n}$ and $A_{2}$ values obtained from these data are listed in Table I. The molecular weight dependence of $A_{2}{ }^{\text {osm }}(M)$ is compared with that of $A_{2}{ }^{1 \mathrm{~s}}(M)$ in Figure 2. It is apparent that for $M>4.5 \times 10^{4}, A_{2}{ }^{\text {osm }}(M)$ and $A_{2}{ }^{1 \text { s }}(M)$ agree fairly well both in magnitude and in the slope of $\log A_{2}-\log M$ plot. A value of -0.19 is obtained for the slope of $\log A_{\mathrm{s}}{ }^{\text {osm }}-\log M$ plot, in close agreement with the value of -0.189 from light scattering measurements at $25^{\circ} \mathrm{C} .^{1}$ Both are close to the value -0.20 predicted by scaling theory. ${ }^{6}$

For $M<3 \times 10^{4}$, however, $A_{2}{ }^{\text {osm }}$ is very much larger than $A_{2}{ }^{1 \text { s }}$. Our use of nearly monodisperse PS samples precludes any possibility of interpreting this large difference as due to the polydisperse effect discussed by Tanaka and Solc. ${ }^{7}$ The origin is not understood at the present moment. For $M<3 \times 10^{4}$ both osmotic pressure and light scattering measurements were made in the same concentration range, while for $M>3 \times 10^{4}$ the light scattering experiments were performed at concentrations at least one order of magnitude smaller than those in the osmotic pressure measurements. For samples of $M<4 \times 10^{4}$, linear plots of $\pi / c$ vs. $c$ gave $M_{n}$ and $A_{2}$ values which were in close agreement with those from square root plots.

It has been reported in literature ${ }^{8-10}$ that in the MW region of $M<2 \times 10^{4}$ the value of $A_{2}$ increased rapidly with decreasing $\mathrm{MW}$. A

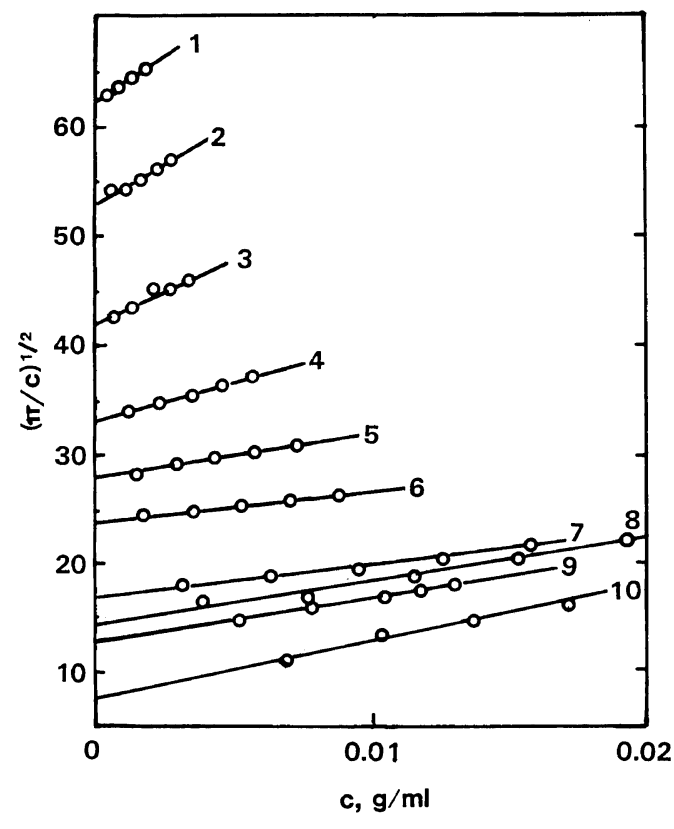

Figure 1. Osmotic pressure data for PS samples No. $1-10$ in toluene at $30.0^{\circ} \mathrm{C}$. $\pi$ in $\mathrm{g} \mathrm{cm}^{-2}, c$ in $\mathrm{g} \mathrm{ml}^{-1}$.

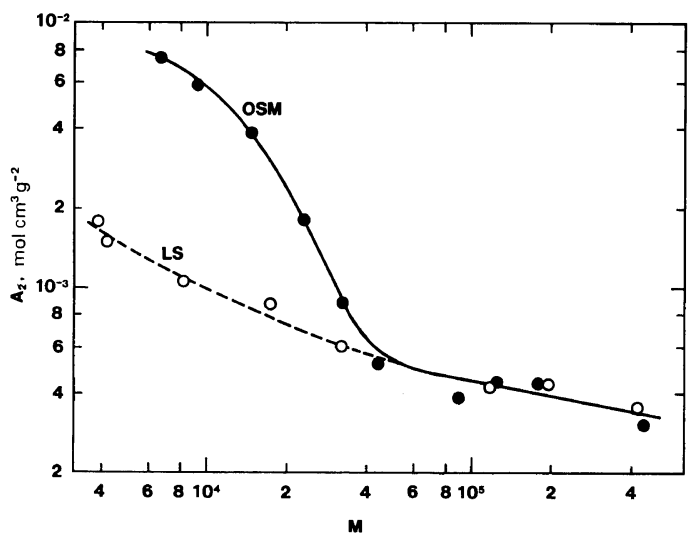

Figure 2. MW dependence of $A_{2}$ of PS-toluene system at $30.0^{\circ} \mathrm{C}: \bigcirc, A_{2}^{\text {osm }} ; \bigcirc, A_{2}^{\text {ls }}$.

linear relationship between $A_{2}$ and $M^{-1 / 2}$ has been found to fit the experimental data in this MW range. ${ }^{1,9,11}$ The present data conform to this relation as well in the MW range (630) $\times 10^{3}$ :

$$
A_{2}=0.964 M^{-1 / 2}-4.36 \times 10^{-3}
$$

However, these values for the intercept and 
slope of the $A_{2}$ vs. $M^{-1 / 2}$ plot differ considerably from those obtained by light scattering experiments. ${ }^{1}$

Even from the rather scanty experimental studies on low MW flexible polymers in good solvents it seems clear cut that the behavior of $A_{2}(M)$ changes rather abruptly when MW is lowered below a certain value. This critical MW appears to coincide with the MW below which the polymer coil in a good solvent will no longer be expanded by solvent swelling. ${ }^{9}$ Further studies in this MW region are certainly needed to attain a thorough understanding of the transition of dilute solution properties in moving from oligomers to high MW polymers.

Acknowledgement. We wish to thank Professor M. Seno of Tokyo University for his favor in using an automatic membrane osmometer of Wescan Inc. in the university.

\section{REFERENCES}

1. Q. Ying and R. Qian, Scientia Sinica (Chinese ed), 961 (1982).

2. L. Zhang and G. Zhou, Polym. Commun. (China), 290 (1981)

3. L. Zhang and D. Zhan, Polym. Commun. (China), 115 (1984).

4. W. Kuhn, Z. Elekrochem., 55, 207 (1951).

5. P. J. Flory, "Principles of Polymer Chemistry," Cornell University Press, Ithaca, N.Y., 1953, p 280.

6. P. G. de Gennes, "Scaling Concepts in Polymer Physics," Cornell University Press, Ithaca, N.Y., 1979, p 78.

7. G. Tanaka and K. Solc, Macromolecules, 15, 791 (1982).

8. H. G. Elias and R. Schumacher, Makromol. Chem., 76, 23 (1964).

9. C. Rossi, E. Bianchi, and E. Pedemonte, Makromol. Chem., 89, 95 (1965).

10. Г.И. Тимофеева, С.А. Павлова, Н.М. Коцоева, В.В. Коршак, Высокомол. Соедин., Сер. В, 15, 816 (1973).

11. H. Sotobayashi and K. Ueberreiter, J. Polym. Sci., $A, 2,1257$ (1964). 